\section{The Health of Hispanic Children from Birth to Emerging Adulthood}

\author{
By \\ KRISTA M. PERREIRA \\ and \\ CHENOA D. ALLEN
}

This article summarizes frameworks for understanding Hispanic children's health, sources of national data available to evaluate their health, and variations in health among Hispanic children. Following ecological and life-course perspectives, we organize our review of the literature on Hispanic children's health and development according to three key stages of child development (zero to three, early to middle childhood, and adolescence to emerging adulthood) with attention to how each stage influences the next. Within each stage, we consider how social position (i.e., skin color, social class, gender, and nativity), social contexts (i.e., family, school, and neighborhood), and political and legal contexts influence Hispanic children's health and development. We argue that to improve the health and development of Hispanic children, federal, state, and local policies must address social and economic injustices that lead to declines in health across immigrant generations and persistent racial/ethnic health disparities.

Keywords: Hispanic/Latino; child health; child development; mental health; social determinants

Children's physical and mental health provides the foundation for their education, employment, and long-term well-being as adults (Perreira and Ornelas 2011). Given the importance of social determinants (e.g., discrimination, education, and poverty) in health,

Krista M. Perreira is a professor of social medicine at the University of North Carolina School of Medicine at Chapel Hill. Her scholarship combines qualitative and quantitative methodologies to study Hispanic/Latino health, immigration, and the consequences of structural inequalities and public policies affecting Hispanicl Latino and immigrant populations.

Chenoa D. Allen is an assistant professor of health sciences at the University of Missouri and a research affiliate at the University of Wisconsin Center for Demography of Health and Aging. Her current work studies the effects of state and local immigrant policies on Hispanic children's health.

Correspondence: perreira@email.unc.edu

DOI: $10.1177 / 00027162211048805$ 
improvements in children's health require investments not only in medical services but also in the public health, education, and social service infrastructures that promote health (Taylor et al. 2016).

Yet there are limits to federal, state, and local government investments in children's health. While access to public health insurance via Medicaid has expanded greatly since the 1980s (Perreira, Allen, and Oberlander, this volume), government commitments to other policies that impact children's health have been constrained. In 1996, Congress passed welfare reforms limiting access to cash and food assistance for low-income families. The onset of the COVID-19 pandemic created additional fiscal challenges for governments and at the same time spurred federal investments in families with children. However, it is unclear if these investments will continue going forward.

To address health disparities and promote health equity, investments in policies and programs to promote children's well-being are especially important for historically marginalized and underserved populations, including Hispanic children. This article summarizes frameworks for understanding Hispanic children's health, sources of national data available to evaluate their health, and differences in health among Hispanic children. We conclude with a discussion of the potential effects of COVID-19 on the health of Hispanic children and the strategies needed to protect their health.

\section{Frameworks for Understanding Hispanic Children’s Health}

Ecological systems and life-course perspectives frame most research on children's health and development. The ecological perspective emphasizes that, apart from the family, children are influenced by multiple, nested systems (also referred to as environmental contexts), the interactions between these systems, and changes over time in these systems (Bronfrenbrenner 2005). Systems include microsystems (e.g., extended family, schools, and neighborhoods) that are most central to children's lives and daily experiences; exosystems (e.g., social agencies and employers), which influence the availability of resources for children; and macrosystems (e.g., governments and cultures), which influence broader social structures, values, and norms. Heavily influenced by the life-course perspective, later renditions of the ecological systems perspective (inclusive of personprocess-context-time models and bioecological models) emphasized the agency of children and their unique dispositions in affecting interactions (i.e., processes) with people and contexts across different aspects of time (age, birth cohorts, and historical periods).

NOTE: This research was supported by the Carolina Population Center and its National Institutes of Health (NIH)/National Institute of Child Health and Human Development (NICHD) Grant Award Number P2C HD50924 and the Integrating Special Populations/ North Carolina Translational and Clinical Sciences Institute through Grant Award Number UL1TR002489 (Perreira). 
The life-course perspective emphasizes (1) the connections between health and development across different ages from birth to death, (2) the particular timing of experiences within a child's life, (3) the embeddedness of children's lives in historical times and places, (4) the links between children's lives and the lives of their family and community members, and (5) the agency of children and parents in influencing their circumstances and life-course trajectories (Elder, Johnson, and Crosnoe 2003). Grounded in life-course theory, health researchers have identified significant associations between children's health across developmental periods from ages 0 to 3 , early (ages 4-8) to middle (ages 9-11) childhood, adolescence (ages 12-18) to emerging adulthood (ages 19-25), and ultimately into adulthood. These associations stem from exposures affecting children at critical or sensitive periods in their lives, the accumulation of risks over the life course, and sequences of events and exposures that can both mediate and moderate risks from previous developmental periods.

Both the ecological and life-course perspectives have been criticized for their lack of explicit attention to the normative experiences of minority children, including Hispanic children and children of immigrants, and for their emphasis on deficits rather than assets or competencies (García Coll et al. 1996; Torres and Young 2016). First proposed by García Coll et al. (1996), the integrative model for the study of child development has become a central framework in research on racial/ethnic disparities in child development by recentering these perspectives around systems of social stratification in the United States. These include race/ethnicity, skin color, social class, and gender. It then focuses attention on the mechanisms (i.e., racism, prejudice, oppression, and segregation) used to produce social stratification. Finally, it highlights the adaptive responses that children and families adopt in reaction to mechanisms of social stratification and environmental contexts that can both promote and inhibit children's development.

For the health and development of Hispanic children, migration is an enduring theme. Although the vast majority of Hispanic children are U.S. born, 55 percent have at least one immigrant parent, and an estimated 25 to 28 percent have a parent who was an unauthorized immigrant (Clarke, Turner, and Guzman 2017). Children with two unauthorized parents have worse health than those with only one unauthorized parent, and mother's nativity and legal status may matter more than father's for children's health (Oropesa, Landale, and Hillemeier 2015). Thus, ecological and life-course models of Hispanic children's development must also incorporate multiple dimensions of immigration background (i.e., child's nativity, parent's nativity, and legal status) as key components of social stratification (Torres and Young 2016; Suárez-Orozco et al. 2018).

Historically, this literature focused on the immigrant paradox. The immigrant paradox refers to the fact that, despite lower socioeconomic status (SES), firstgeneration (i.e., foreign-born children with foreign-born parents) children in immigrant families often have better health and developmental outcomes than their second-generation (i.e., U.S.-born children with foreign-born parents) or third-generation (U.S.-born children with U.S.-born parents) coethnic peers. The first immigrant generation potentially benefits from an optimistic outlook 
and a dual frame of reference that views their postmigration circumstances as an improvement upon their premigration circumstances. Additionally, they may benefit from living in coethnic neighborhoods that provide a source of social cohesion and belonging and buffer children from exposure to discrimination (García Coll et al. 1996; Suárez-Orozco et al. 2018). Coethnic neighborhoods are generally found to be protective for health, but not in all contexts or for all subgroups. However, the paradox is not universal, and some groups of foreign-born Hispanic children such as those who are refugees, asylees, or unauthorized immigrants may be at higher risk of poor physical and mental health than their secondor third-generation coethnic peers (Suárez-Orozco et al. 2018). For these youth, it is especially important to understand how experiences before, during, and after migration influence their health and development (Perreira and Ornelas 2011).

More recently, the literature on children's health and development has recognized that the well-being of children of immigrants can be strongly affected by the sociopolitical climate in which they grow up (Suárez-Orozco et al. 2018). Welcoming communities and positive attitudes toward immigrants can facilitate their integration and promote child well-being, while hostility, fear, and prejudice can hinder integration and inhibit healthy development. Moreover, children's health and development can be profoundly influenced by federal immigration and naturalization laws; immigration enforcement activities; and federal, state, and local laws affecting access to education, health, and human services in the United States.

During the past several decades, four sets of laws have substantially influenced the well-being of children in immigrant families, including Hispanic children (Perreira and Pedroza 2019). In 1986, Congress passed the Immigration Reform and Control Act (IRCA86). This act allowed millions of unauthorized immigrants and seasonal agricultural workers living in the United States prior to 1982 to become legal U.S. residents. At the same time, the act introduced sanctions for employers who knowingly hired unauthorized immigrants. In 1996, Congress passed the Personal Responsibility and Work Opportunity Reconciliation Act of 1996 (PRWORA). This act restricted access to public assistance programs (e.g., cash, food, and medical assistance programs) for many lawfully present immigrants who arrived in the United States after 1996. In the 2000s, local law enforcement jurisdictions working with Immigration and Customs Enforcement (ICE) began implementing Section 287(g) of the Illegal Immigration Reform and Immigrant Responsibility Act (IIRIRA). These $287(\mathrm{~g})$ programs and subsequent Secure Communities (SComm) programs allowed state and local law enforcement to participate in enforcing immigration laws throughout the interior of the United States. Prior to the implementation of these programs, most ICE activities occurred within one hundred miles of the U.S. border. In 2012, U.S. Citizenship and Immigration Services (USCIS) began implementing Deferred Action for Childhood Arrivals (DACA). DACA has allowed approximately 640,000 unauthorized immigrants to remain in the United States and work with legal authorization (Migration Policy Institute 2020). These laws have direct effects on first- and second-generation children with immigrant parents; they also have indirect effects on U.S.-born Hispanic youth whose parents are U.S. citizens, but who live in communities and extended families with immigrants (Perreira and Pedroza 2019). 
Following ecological and life-course perspectives, we organize our review of the literature on Hispanic children's health and development according to three key stages of child development (zero to three, early to middle childhood, and adolescence to emerging adulthood) with attention to how each stage influences the next. Within each stage, we consider how social position (i.e., skin color, social class, gender, and nativity), social contexts (i.e., family, school, and neighborhood), and political and legal contexts influence Hispanic children's health and development.

\section{Measuring Hispanic Children’s Health}

\section{National datasets}

Several types of data are currently available to evaluate the health of Hispanic children. However, they vary in terms of the breadth of health information collected and the availability of information on parent's and children's nativity, Hispanic background or heritage (e.g., Central American, Cuban, Dominican, Mexican, Puerto Rican, or South American), or other social determinants of health (e.g., socioeconomic background). Moreover, few federal data collection efforts on children's health include the U.S. territory, Puerto Rico, which is home to nearly 3.2 million people, including approximately 600,000 children (U.S. Census Bureau 2020).

The National Center for Health Statistics routinely collects data on births, deaths, and infectious diseases through (1) the National Vital Statistics System (NVSS), including linked birth and infant death data; (2) the National Longitudinal Mortality Study (NLMS); and (3) the National Notifiable Disease Surveillance System (NNDSS). These three datasets include a large number of the U.S. population (including those living in U.S. territories) with information on mother's or child's nativity, Hispanic background, and detailed geographic information that allows for county- and state-level estimates. The breadth of information on health and socioeconomic status (SES) background is limited.

More comprehensive information on the health of Hispanic children can be obtained from repeated cross-sectional surveys, which include large, nationwide samples of Hispanic children (see Table 1). Nearly all of these surveys collect data in both Spanish and English, a factor essential to accurately representing the Hispanic population in the United States. The largest of these cross-sectional datasets, the National Health Interview Survey (NHIS), currently includes parents' assessments of their children's general health status, height and weight, mental health (e.g., anxiety, depression, behavioral problems), and health behaviors (e.g., physical activity, screen time, and sleep). Additionally, it includes data on physical health conditions (e.g., asthma, diabetes) and developmental or learning delays diagnosed by a physician or other health professional. The National Survey of Children's Health (NSCH) contains questions on children's health similar to those available in NHIS and, like NHIS, relies on parental reports. The National Health and Nutrition Examination Survey (NHANES) 
TABLE 1

Key National Datasets Measuring Health of Latino Children (0-18)a

\begin{tabular}{|c|c|c|c|c|c|}
\hline Dataset Name & Data Type & $\begin{array}{l}\text { Primary } \\
\text { Respondent }\end{array}$ & $\begin{array}{l}\text { Children's } \\
\text { Ages }\end{array}$ & Year(s) Started & $\begin{array}{c}\text { Hispanic } \\
\text { Sample Size }\end{array}$ \\
\hline $\begin{array}{l}\text { National Health Interview } \\
\text { Survey (NHIS) }\end{array}$ & $\begin{array}{l}\text { Annual } \\
\text { cross-section }\end{array}$ & Parent & $0-18$ & 1957 & 4,041 \\
\hline $\begin{array}{l}\text { National Health and Nutrition } \\
\text { Examination Survey } \\
\text { (NHANES)c }\end{array}$ & $\begin{array}{l}\text { Annual } \\
\text { cross-section }\end{array}$ & Parent & $0-17$ & 1999 & 852 \\
\hline $\begin{array}{l}\text { National Survey of Children's } \\
\text { Health (NSCH) }\end{array}$ & $\begin{array}{l}\text { Cross-section } \\
\text { every } 4 \text { years }^{\mathrm{d}}\end{array}$ & Parent & $0-17$ & 2003 & 3,622 \\
\hline $\begin{array}{l}\text { National Survey on Drug Use } \\
\text { and Health (NSDUH) }\end{array}$ & $\begin{array}{l}\text { Annual } \\
\text { cross-section }\end{array}$ & Child & $12-17$ & 1971 & 3,012 \\
\hline Monitoring the Future Studye & $\begin{array}{l}\text { Annual } \\
\text { cross-section }\end{array}$ & Child & $12-18$ & 2006 & 9,160 \\
\hline $\begin{array}{l}\text { Youth Risk Behavior } \\
\text { Surveillance System (YRBSS) }\end{array}$ & $\begin{array}{l}\text { Biennial } \\
\text { cross-section }\end{array}$ & Child & $14-18$ & 1991 & 3,636 \\
\hline $\begin{array}{l}\text { Fragile Families and Child } \\
\text { Well-Being Study } \\
\text { (FFCWS),f,g }\end{array}$ & $\begin{array}{l}\text { 15-year } \\
\text { longitudinal }\end{array}$ & Parent & Birth (0) & 1998-2000 & 930 \\
\hline $\begin{array}{l}\text { Early Childhood Longitudinal } \\
\text { Study, Birth Cohort (ECLS- } \\
\text { B)g }\end{array}$ & $\begin{array}{l}\text { 6-year } \\
\text { longitudinal }\end{array}$ & Child & 9 months & 2001-2002 & 2,200 \\
\hline $\begin{array}{l}\text { Early Childhood Longitudinal } \\
\text { Study, Kindergarten Cohort } \\
\text { (ECLS-K)g }\end{array}$ & $\begin{array}{l}\text { 9-year } \\
\text { longitudinal }\end{array}$ & Child & $4-6$ & 1998-1999 & 941 \\
\hline $\begin{array}{l}\text { Early Childhood Longitudinal } \\
\text { Study, Kindergarten Cohort } \\
\text { (ECLS-K:2011)g }\end{array}$ & $\begin{array}{l}\text { 6-year } \\
\text { longitudinal }\end{array}$ & Child & $4-6$ & $2010-2011$ & 4,832 \\
\hline $\begin{array}{l}\text { National Longitudinal Study of } \\
\text { Adolescent to Adult Health } \\
\text { Study (Add Health)c,f,g }\end{array}$ & $\begin{array}{l}\text { 24-year } \\
\quad \text { longitudinal }\end{array}$ & Child & $12-18$ & 1994-1995 & 3,525 \\
\hline $\begin{array}{l}\text { National Longitudinal Survey } \\
\text { of Youth 1997 Cohort } \\
\text { (NLSY97) f,g }\end{array}$ & $\begin{array}{l}\text { 20-year } \\
\text { longitudinal }\end{array}$ & Child & $12-17$ & 1997 & 1,901 \\
\hline
\end{tabular}

a. We do not include information in the table from single cross-sections that have not been repeated or longitudinal cohorts established prior to 1990.

b. Child's race/ethnicity, reported by primary respondent. Sample sizes are for children only. For longitudinal studies, the age of children and sample size reflect the sample at the start of data collection. For cross-sectional studies, the sample size is an estimated sample for the most recent cross-section.

c. Includes direct measures of biomarkers, e.g., height; weight; blood pressure; blood, saliva, and urine samples.

d. Since 2016, data have been collected annually.

e. Although the study began collecting data in 1975 , race/ethnicity data were not collected until 2006.

f. Ongoing longitudinal study.

g. Includes in-person developmental/cognitive testing. 
complements NHIS and NSCH with more detailed data on children's diets and physical activity. Most importantly, it includes a physical exam to directly measure critical aspects of health (e.g., height, weight, blood pressure, cholesterol, and blood glucose levels) rather than relying on self-reports or parental reports. The National Survey on Drug Use and Health (NSDUH) also complements NHIS and NSCH by collecting detailed information on alcohol, tobacco and other drug use (ATOD), and mental health from children ages 12 to 17. Additionally, the Monitoring the Future (MTF) project collects detailed ATOD data but provides more information than NSDUH on the family, peer, and school characteristics that may influence ATOD use. Finally, with a focus on children in grades nine through twelve, the Youth Risk Behavior Surveillance System (YRBSS) provides data on the physical health, mental health, and health behaviors (diet, physical activity, and ATOD) essential to monitoring the well-being of adolescents. It is the only federal survey of children's health collected routinely in Puerto Rico.

While repeated cross-sections provide information on the well-being of children in the United States over time, they do not allow researchers to understand the development of cohorts of children through time. For this, longitudinal data on Hispanic children are needed (see Table 1). Since the late 1990s or early 2000s, two birth cohorts have been available: (1) The Fragile Families and Child Well-Being Study (FFCWBS), which is ongoing; and (2) the Early Childhood Longitudinal Study-Birth Cohort (ECLS-B), which ended in 2007-2008. Two kindergarten cohorts have been available through the Early Childhood Longitudinal Study (ECLS) program. One, the ECLS-K, started in 1998-1999 and ended in 2007-2008. The second, the ECLS-K:2011, started in 2010-2011 and ended in 2016-2017. Finally, two adolescent cohorts are available and data collection from these cohorts is on-going. They include the National Longitudinal Study of Adolescent to Adult Health (Add Health) and the National Longitudinal Survey of Youth 1997 Cohort (NLSY97). These two cohorts have the potential to help us better understand how adolescent health affects adult health. At the same time, they provide no information on Hispanic children growing up in the United States today since these adolescent cohorts have already entered adulthood.

In a 2014 report, the Administration for Children and Families (ACF) recommended that all studies including Hispanic populations collect not only data on race and Hispanic ethnicity but also data on Hispanic background, parents' country of birth, children's country of birth, U.S. citizenship, and language spoken at home (Office of Planning, Research \& Evaluation [OPRE] 2014). These measures are essential for understanding variation in health outcomes within the Hispanic population. However, few federal datasets include each of these measures. The NHIS contains information on parents' and children's nativity, years in United States, Hispanic background, and citizenship. The NSCH contains parent's and children's nativity, years in the United States, Hispanic background, and language spoken in the home. The NSDUH contains information on only English language fluency and child's country of birth, and the MTF project and YRBSS contain only race and Hispanic ethnicity. In contrast to many of the cross-sectional datasets, the longitudinal studies include relatively comprehensive data on the demographic and SES characteristics of children and their families, including nearly all the 
elements recommended by ACF. However, with the exception of data collected through the ECLS program and NLSY97, these longitudinal datasets only include children who can complete survey instruments in English.

These existing national datasets provide a wide range of measures of physical health, mental health, and health behaviors, allowing for a broad understanding of the health advantages and disadvantages of Hispanic children overall and about the differences in health for U.S.-born Hispanic children of immigrants, compared to U.S.-born Hispanic children of U.S.-born parents. However, due to small sample sizes, we know less about health status for foreign-born children or about differences in health by Hispanic background. Currently, no longitudinal cohort studies exist of today's young children, limiting researchers' ability to investigate how the current sociopolitical environment affects Hispanic children as they age. Consequently, the ECLS-K:2024, which will begin following a national cohort of children who enter kindergarten in 2023-2024, will become an essential resource for future research.

\section{Key health indicators}

Using recent cross-sectional data available through the NVSS, NHIS, NSCH, NSDUH, and YRBSS, we identified several racial/ethnic disparities across key health indicators (see Table 2). Infant health indicators reveal few differences. Rates of preterm births did not differ by race/ethnicity. But Hispanic women had higher rates of low birthweight than non-Hispanic (NH) white women and lower rates of low birthweight than NH Black women. Additionally, Hispanic children were more likely to have never been breastfed than NH white children.

As children age, more disparities surface. In comparison to parents of $\mathrm{NH}$ white children, parents of Hispanic children (0-17) report significantly higher rates of fair to poor health among their children and higher rates of overweight and obesity. But diagnosed asthma and diabetes rates among Hispanic children do not differ from $\mathrm{NH}$ white children and are significantly lower than among $\mathrm{NH}$ Black children. Moreover, food insecurity is nearly twice as prevalent among children in households headed by Hispanic or NH Black adults than in households headed by NH white adults (Coleman-Jensen et al. 2017). Physical inactivity among Hispanic children is greater than among $\mathrm{NH}$ white children. At the same time, the mental, emotional, developmental, and behavioral health of Hispanic children is similar to or better than the health of NH white and NH Black children. However, these comparisons rely on parents' reports of diagnoses by physicians or other health professionals. As discussed by Perreira, Allen, and Oberlander (this volume), Hispanic children are less likely to have health insurance and regular doctor's visits. Thus, their health problems may be under diagnosed.

Focusing on adolescents, we identify high rates of overweight and obesity among Hispanic children and some evidence of poor diet (e.g., no vegetable consumption). At the same time, the positive mental health of children has begun to erode. Hispanic adolescents report rates of sadness or hopelessness, major depressive episodes, suicidality, and ATOD use similar to rates reported by $\mathrm{NH}$ white children and, in some cases, higher than rates reported by NH Black children. 
TABLE 2

Physical, Mental, and Behavioral Health of NH Black, NH White, and Hispanic Children

NH White NH Black Hispanic

Infant health

Infant deaths per 1,000 live births (NVSS 2017)

Low birthweight (\%, NSCH 2016-2018)

Preterm births (\%, NSCH 2016-2018)

Never breastfed (\%, NSCH 2016-2018)

Overall child health

Fair-poor health (\% ages 3-17, NSCH 2016-2018)

Overweight or obese (\% ages 10-17, NSCH 2016-2018)

Physically inactive in past week (\% ages 6-17, NSCH 2016-2018)

Diagnosed with any chronic physical condition (\% ages $3-17$,

NSCH 2016-2018)

Diagnosed with asthma (\% ages 3-17, NSCH 2016-2018)

Diagnosed diabetes (per 1,000) (ages 3-17, NSCH 2016-2018)

Diagnosed with any mental, emotional, developmental or behavioral problems (\% ages 3-17, NSCH 2016-2018)

Diagnosed depression (\% ages 3-17, NSCH 2016-2018)

Diagnosed anxiety problem (\% ages 3-17, NSCH 2016-2018)

Diagnosed with ADD/ADHD (\% ages 3-17, NCHS 2016-2018)

Adolescent physical health

Diagnosed with asthma (\%, YRBSS 2017)

Overweight or obese (\%, YRBSS 2017)

Physically inactive in past week (\%, YRBSS 2017)

Adolescent dietary behaviors (in past 7 days)

Skipped breakfast at least once (\%, YRBSS 2017)

Drank soda at least once/day (\%, YRBSS 2017)

Consumed no fruit (\%, YRBSS 2017)

Consumed no vegetables (YRBSS 2017)

Adolescent mental health

Major depressive episode in past year (\% ages 12-17,

NSDUH 2017)

Suicidality (\%, YRBSS 2017)

Felt unsafe going to school (\%, YRBSS 2017)

Adolescent sexual behavior

Had first sexual intercourse before age 13 (\%, YRBSS 2017)

Currently sexually active (\%, past 3 months, YRBSS 2017)

No birth control at last sexual intercourse (\%, YRBSS 2017)

Adolescent alcohol, tobacco, other drug use

Used tobacco past 30 days (\%, YRBSS 2017)

Drank alcohol past 30 days (\%, YRBSS 2017)

Used marijuana past 30 days (\%, YRBSS 2017)

$\begin{array}{rrr}4.7 & 11.0^{\mathrm{a}} & 5.1^{\mathrm{b}} \\ 7.6 & 13.9^{\mathrm{a}} & 9.5^{\mathrm{a}, \mathrm{b}} \\ 10.8 & 12.6^{\mathrm{a}} & 12.4 \\ 16.2 & 33.9^{\mathrm{a}} & 24.5^{\mathrm{a}, \mathrm{b}}\end{array}$

25.9

$38.8^{\mathrm{a}}$

$2.4^{\mathrm{a}}$

7.5

$13.7^{\mathrm{a}}$

$38.3^{\mathrm{a}}$

$\begin{array}{lll}7.4 & 15.8^{\mathrm{a}} & 8.5^{\mathrm{b}}\end{array}$

$\begin{array}{lll}4.3 & 11.0 & 2.6^{\mathrm{b}}\end{array}$

$25.0 \quad 25.6 \quad 20.7^{\mathrm{a}, \mathrm{b}}$

$\begin{array}{lll}3.7 & 3.7 & 2.3^{\mathrm{a}, \mathrm{b}}\end{array}$

$\begin{array}{lll}9.3 & 4.8^{\mathrm{a}} & 5.6^{\mathrm{a}}\end{array}$

$\begin{array}{lll}9.8 & 10.8 & 6.7^{\mathrm{a}, \mathrm{b}}\end{array}$

$20.9 \quad 29.8^{\mathrm{a}} \quad 21.1^{\mathrm{b}}$

$26.5 \quad 36.0^{\mathrm{a}} \quad 37.7^{\mathrm{a}}$

$\begin{array}{lll}13.6 & 19.8^{\mathrm{a}} & 16.1\end{array}$

$\begin{array}{lll}12.8 & 15.2 & 16.0\end{array}$

$\begin{array}{lll}19.6 & 21.5 & 17.0^{\mathrm{b}}\end{array}$

$\begin{array}{lll}5.5 & 7.0 & 5.0\end{array}$

$\begin{array}{lll}5.3 & 12.7^{\mathrm{a}} & 9.2^{\mathrm{a}}\end{array}$

$14 \quad 9.5^{\mathrm{a}} \quad 13.8^{\mathrm{b}}$

$\begin{array}{lll}17.4 & 14.7 & 16.4\end{array}$

$\begin{array}{lll}4.9 & 9.0^{\mathrm{a}} & 9.4^{\mathrm{a}}\end{array}$

$2.1 \quad 7.5^{\mathrm{a}} \quad 4.0^{\mathrm{a}, \mathrm{b}}$

$\begin{array}{lll}28.8 & 31.3 & 29.2\end{array}$

$10.0 \quad 17.8^{\mathrm{a}} \quad 19.0^{\mathrm{a}}$

$22.4 \quad 14.9^{\mathrm{a}} \quad 16.6$

$32.4 \quad 20.8^{\mathrm{a}} \quad 31.3^{\mathrm{b}}$

$\begin{array}{lll}17.7 & 25.3^{\mathrm{a}} & 23.4\end{array}$

SOURCE: NVSS (2017); NSCH (2016-2018); NSDUH (2017); YRBSS (2017).

a. Significantly different at $p<.05$ from $\mathrm{NH}$ white persons.

b. Significantly different at $p<.05$ from NH Black persons. 
TABLE 3

Physical, Mental, and Behavioral Health of Hispanic Children by Child's and Parent's Nativity

\begin{tabular}{|c|c|c|c|c|c|c|}
\hline & \multicolumn{2}{|c|}{$\begin{array}{c}\text { First } \\
\text { Generation } \\
(\operatorname{Max} N=452)\end{array}$} & \multicolumn{2}{|c|}{$\begin{array}{c}\text { Second } \\
\text { Generation } \\
(\operatorname{Max} N=4,712)\end{array}$} & \multicolumn{2}{|c|}{$\begin{array}{c}\text { Third } \\
\text { Generation } \\
(\operatorname{Max} N=5,516)\end{array}$} \\
\hline & $\%$ & $(S E)$ & $\%$ & $(S E)$ & $\%$ & $(S E)$ \\
\hline \multicolumn{7}{|l|}{ Mother's health } \\
\hline Physical health fair-poor & 8.79 & $(2.99)$ & 7.72 & $(0.82)$ & 7.88 & $(0.80)$ \\
\hline Mental/emotional health fair-poor & 1.31 & $(0.56)$ & 3.03 & $(0.42)$ & 7.03 & $(0.79)^{\mathrm{a}, \mathrm{b}}$ \\
\hline \multicolumn{7}{|l|}{ Infant health, ages $0-17$} \\
\hline Preterm births & 9.06 & $(1.88)$ & 11.99 & $(1.12)$ & 13.67 & $(1.07)$ \\
\hline Low birthweight & 12.15 & $(3.22)$ & 9.29 & $(0.98)$ & 9.24 & $(0.78)$ \\
\hline Never breastfed (ages $0-5$ ) & 7.08 & $(4.56)$ & 14.02 & $(1.83)$ & 27.64 & $(2.79)^{\mathrm{b}}$ \\
\hline \multicolumn{7}{|l|}{ Overall child health, ages 3-17 } \\
\hline Fair-poor health & 2.42 & $(0.92)$ & 2.31 & $(0.42)$ & 2.65 & $(0.64)$ \\
\hline Any adverse childhood experiences & 37.12 & $(4.25)$ & 28.77 & $(1.48)$ & 46.67 & $(1.57)^{\mathrm{b}}$ \\
\hline Diagnosed with any chronic physical condition & 24.12 & $(3.06)$ & 36.86 & $(1.60)^{\mathrm{a}}$ & 47.06 & $(1.56)^{\mathrm{a}, \mathrm{b}}$ \\
\hline Diagnosed with asthma & 3.16 & $(1.06)$ & 7.40 & $(0.92)^{\mathrm{a}}$ & 11.37 & $(0.90)^{\mathrm{a}, \mathrm{b}}$ \\
\hline $\begin{array}{l}\text { Diagnosed with diabetes (Type } 1 \text { or Type } 2 \text { ) } \\
\quad \text { (per } 1,000)\end{array}$ & 3.10 & $(2.60)$ & 1.60 & $(0.00)$ & 4.10 & $(1.70)$ \\
\hline $\begin{array}{l}\text { Diagnosed with any mental, behavioral, } \\
\text { emotional, or developmental disorder }\end{array}$ & 18.52 & $(4.13)$ & 16.25 & $(1.22)$ & 27.31 & $(1.34)^{\mathrm{b}}$ \\
\hline Diagnosed depression & 1.79 & $(0.93)$ & 1.51 & $(0.30)$ & 3.46 & $(0.24)^{\mathrm{b}}$ \\
\hline Diagnosed anxiety problem & 6.54 & $(2.73)$ & 4.24 & $(0.57)$ & 7.83 & $(0.67)^{\mathrm{b}}$ \\
\hline Diagnosed behavioral/conduct problem & 1.60 & $(0.55)$ & 4.07 & $(0.67)^{\mathrm{a}}$ & 8.03 & $(0.72)^{\mathrm{a}, \mathrm{b}}$ \\
\hline Diagnosed with ADD/ADHD & 5.86 & $(3.08)$ & 3.91 & $(0.59)$ & 10.18 & $(0.84)^{\mathrm{b}}$ \\
\hline \multicolumn{7}{|l|}{ Child health, ages 6-17 } \\
\hline $\begin{array}{l}\text { Child is flourishing (e.g., inquisitive, calm, } \\
\text { task oriented) }\end{array}$ & 87.11 & $(3.64)$ & 90.06 & $(1.15)$ & 89.57 & $(0.89)$ \\
\hline School absence $>2$ wks per year & 3.83 & $(1.83)$ & 2.63 & $(0.65)$ & 6.33 & $(0.94)^{\mathrm{b}}$ \\
\hline No participation in sports in past year & 55.03 & $(4.60)$ & 54.56 & $(1.85)$ & 43.27 & $(1.72)^{\mathrm{b}}$ \\
\hline No physical activity in past week & 20.40 & $(4.05)$ & 9.82 & $(1.03)^{\mathrm{a}}$ & 7.14 & $(0.70)^{\mathrm{a}}$ \\
\hline Less than 6 hours of sleep & 1.16 & $(0.77)$ & 1.21 & $(0.25)$ & 2.01 & $(0.48)$ \\
\hline \multicolumn{7}{|l|}{ Child health, ages 10-17 } \\
\hline Overweight or obese & 25.72 & $(4.33)$ & 40.01 & $(2.24)^{\mathrm{a}}$ & 36.74 & $(2.08)$ \\
\hline Bullied weekly (2018 only) & 0.00 & $(0.00)$ & 3.55 & $(1.39)^{\mathrm{a}}$ & 6.97 & $(1.43)^{\mathrm{a}}$ \\
\hline
\end{tabular}

SOURCE: NSCH (2016-2018).

a. With Bonferroni correction, significantly different at $p<.05$ from first generation.

b. With Bonferroni correction, significantly different at $p<.05$ from second generation.

While informative, these prevalence rates by race/ethnicity obscure differences among Hispanic children by their parents' nativity (Table 3), Hispanic background (Table 4), gender, and SES. We discuss these and other factors influencing the physical, mental, and behavioral health of children in the next sections. 
TABLE 4

Physical, Mental, and Behavioral Health of Hispanic Children by Hispanic Background

\begin{tabular}{|c|c|c|c|c|c|c|c|c|}
\hline & \multicolumn{2}{|c|}{$\begin{array}{c}\text { Central } \\
\text { American } \\
(\operatorname{Max} N=889)\end{array}$} & \multicolumn{2}{|c|}{$\begin{array}{c}\text { Cuban } \\
(\operatorname{Max} N=640)\end{array}$} & \multicolumn{2}{|c|}{$\begin{array}{c}\text { Mexican } \\
(\operatorname{Max} N=20,572)\end{array}$} & \multicolumn{2}{|c|}{$\begin{array}{c}\text { Puerto Rican } \\
(\operatorname{Max} N=2,397)\end{array}$} \\
\hline & $\%$ & $(S E)$ & $\%$ & $(S E)$ & $\%$ & $(S E)$ & $\%$ & $(S E)$ \\
\hline \multicolumn{9}{|l|}{ Mother health } \\
\hline Mother health fair-poor & 8.0 & $(0.8)^{\mathrm{d}}$ & 5.0 & $(1.2)^{\mathrm{d}}$ & 9.4 & $(0.4)^{\mathrm{d}}$ & 13.3 & $(1.3)^{a, b, c}$ \\
\hline \multicolumn{9}{|l|}{ Infant health } \\
\hline Low birthweight $(0-17)$ & 8.3 & $(0.9)$ & 6.5 & $(2.1)$ & 8.4 & $(0.4)$ & 11.5 & (1.3) \\
\hline \multicolumn{9}{|l|}{ Child health } \\
\hline Fair-poor health (3-17) & 2.4 & $(0.4)$ & 2.6 & $(1.0)$ & 2.5 & $(0.2)$ & 2.8 & $(0.5)$ \\
\hline $\begin{array}{l}\text { Any limitations in social/ } \\
\text { physical activity }(3-17)\end{array}$ & 7.3 & $(0.8)^{\mathrm{b}, \mathrm{d}}$ & 3.4 & $(0.9)^{\mathrm{a}, \mathrm{c}, \mathrm{d}}$ & 8.0 & $(0.4)^{\mathrm{b}, \mathrm{d}}$ & 21.1 & $(1.9)^{\mathrm{a}, \mathrm{b}, \mathrm{c}}$ \\
\hline $\begin{array}{l}\text { Diagnosed any chronic physical } \\
\text { condition }(3-17)\end{array}$ & 13.0 & $(1.1)^{\mathrm{d}}$ & 15.6 & $(3.5)^{\mathrm{d}}$ & 14.1 & $(0.5)^{\mathrm{d}}$ & 28.5 & $(2.0)^{a, b, c}$ \\
\hline Diagnosed diabetes (3-17) & 0.0 & $(0.0)$ & 0.4 & $(0.3)$ & 0.1 & $(0.0)$ & 0.2 & $(0.1)$ \\
\hline Diagnosed asthma (3-17) & 11.7 & $(1.0)^{\mathrm{d}}$ & 15.3 & $(3.5)$ & 12.8 & $(0.5)^{\mathrm{d}}$ & 25.7 & $(1.9)^{\mathrm{a}, \mathrm{c}}$ \\
\hline $\begin{array}{l}\text { Diagnosed with ADD/ADHD } \\
(3-17)\end{array}$ & 5.4 & $(0.8)^{\mathrm{d}}$ & 4.5 & $(1.4)^{\mathrm{d}}$ & 5.6 & $(0.4)^{\mathrm{d}}$ & 11.6 & $(1.4)^{a, b, c}$ \\
\hline $\begin{array}{l}\text { Perceived definite or severe } \\
\text { cognitive, behavior, or } \\
\text { emotional difficulties }(4-17)\end{array}$ & 3.1 & $(0.5)^{\mathrm{d}}$ & 1.4 & $(0.9)^{\mathrm{d}}$ & 3.8 & $(0.3)^{\mathrm{d}}$ & 9.8 & $(1.2)^{a, b, c}$ \\
\hline $\begin{array}{l}\text { Missed } 2+\text { wks school due to } \\
\text { illness (ages 5-17) }\end{array}$ & 3.4 & $(0.6)^{\mathrm{d}}$ & 2.6 & $(1.0)^{\mathrm{d}}$ & 3.5 & $(0.3)^{\mathrm{d}}$ & 8.5 & $(1.4)^{a, b, c}$ \\
\hline Overweight or obese (12-17) & 43.6 & $(2.6)$ & 39.8 & $(5.8)$ & 48.2 & $(1.3)$ & 41.1 & $(3.2)$ \\
\hline
\end{tabular}

SOURCE: NHIS (2014-2018) children ages 0-17.

a. With Bonferroni correction, significantly different at $p<.05$ from Central American.

b. With Bonferroni correction, significantly different at $p<.05$ from Cuban.

c. With Bonferroni correction, significantly different at $p<.05$ from Mexican.

d. With Bonferroni correction, significantly different at $p<.05$ from Puerto Rican.

\section{From Zero to Three}

Hispanic mothers have similar or slightly worse birth outcomes compared to NH white mothers (DeSisto and McDonald 2018). Compared to NH white children, Hispanic toddlers demonstrate slower cognitive development from age 9 to 24 months, including slower development of language, problem solving, and motor skills (Fuller et al. 2009). As a result, Hispanic children have lower levels of school readiness than do NH white children at kindergarten entry (Padilla, Cabrera, and West 2017; Padilla and Ryan 2020). However, Hispanic children have similar prosocial skills (e.g., ability to make friends easily, attentiveness in class, shyness) and similar or fewer externalizing behavior problems (e.g., impulsivity, aggression, restlessness) compared to NH white children (Padilla, Cabrera, and West 2017). Disparities in cognitive development, parent-rated health, 
asthma, and weight emerge by preschool entry (Fuller et al. 2009; Dixon, Peña, and Taveras 2012). Emerging disparities in young children's health and development are explained in part by their social position, social contexts, and political and legal contexts.

\section{Social position}

Hispanic infant outcomes differ by Hispanic background, race, socioeconomic status (SES), and nativity. Cuban women have the lowest rates of low birthweight, preterm birth, small for gestational age, and infant mortality; Puerto Rican, Dominican, Guatemalan, and Salvadoran mothers have among the highest rates (DeSisto and McDonald 2018). Differences in health by Hispanic background are likely due to demographic and socioeconomic factors, including nativity, citizenship, skin tone, poverty rates, and the racialization of Hispanics as a marginalized group in the United States. Black Hispanic infants have higher rates of low birthweight and infant mortality than white Hispanic infants (Mydam et al. 2019). Low SES is a risk factor for low birthweight and preterm birth (Kane et al. 2017) and delayed cognitive development (Fuller et al. 2009).

As the literature on the immigrant paradox reflects, foreign-born and lessacculturated mothers tend to have better infant outcomes, compared to their U.S.-born and more-acculturated counterparts. Compared to U.S.-born Hispanic mothers, foreign-born Hispanic mothers have lower rates of low birthweight, preterm birth, and infants who are small for gestational age (DeSisto and McDonald 2018). Breastfeeding rates are higher for foreign-born and Spanish-dominant Hispanic women than for U.S.-born and English-dominant women (U.S. Census Bureau 2019). Evidence about the association between parent nativity and child development is mixed. First- and second-generation Hispanic children have slower rates of cognitive growth (Fuller et al. 2009) but better socioemotional outcomes than third-generation children (Harris and Santos 2020).

\section{Social contexts}

Family-level factors associated with infant and toddler outcomes include family structure, maternal health behaviors, maternal stress and depression, and parent engagement. Most Hispanic infants and children live in two-parent homes (Padilla, Cabrera, and West 2017), which are associated with better birth (Kane et al. 2017) and developmental (Fuller et al. 2009) outcomes. Hispanic mothers, particularly less-acculturated Hispanic mothers, are more likely than NH white mothers to report feeling close to and receiving support from their own mothers and extended family (Fuller et al. 2009). Despite these resources, Hispanic mothers have higher levels of depression, compared to $\mathrm{NH}$ white mothers (Mukherjee et al. 2016). Antenatal depression is associated with preterm birth and low birthweight (Mukherjee et al. 2016), and postpartum depression is associated with slower child cognitive development (Fuller et al. 2009). Poverty and parental stress exacerbate the developmental risks associated with maternal depression (Harris and Santos 2020). 
Parents' engagement in preliteracy activities and cognitive stimulation promote cognitive development and school readiness (Fuller et al. 2009). At kindergarten entry, 97 percent of Hispanic parents report that they or other household members read to their children, and 93 percent engage in other cognitively stimulating activities, at least three days per week. However, Hispanic parents and other family members are less likely than their $\mathrm{NH}$ white counterparts to engage in these activities daily (Padilla, Cabrera, and West 2017). For more information on cognitive development, see Mendez-Smith, Crosby, and Stephens (this volume).

Children's enrollment in center-based early care and education (ECE) promotes cognitive development and may protect against developmental risks associated with low SES (Padilla and Ryan 2020). However, it is unclear what types of center-based ECE programs best promote young children's cognitive development (Padilla and Ryan 2020). Hispanic children with U.S.-born parents are more likely than those with foreign-born parents to be in privately funded centerbased ECE programs, while children with foreign-born parents are more likely to be in family-based care or in Head Start (Padilla and Ryan 2020).

Children's health and development are also shaped by the neighborhoods where they live and attend childcare. Hispanic children are more likely than NH white children to live in disadvantaged neighborhoods with greater poverty and fewer resources (Carlson et al. 2014). Neighborhood disadvantage is associated with higher rates of low birthweight and preterm birth among Hispanic infants (Kane et al. 2017). Segregated schools and neighborhoods may also have health benefits, however, by sheltering youth of color from interpersonal racial/ethnic discrimination and providing cultural compatibility between school and family (Lawton and Gerdes 2014). Furthermore, Hispanic children are disproportionately exposed to air pollution, pesticides, and other environmental contaminants; these exposures are associated with low birthweight, preterm birth, and delayed cognitive and motor development (Vrijheid et al. 2016).

\section{Political and legal contexts}

Studies of the associations between immigrant legal status and health and development are limited because few studies directly measure legal status; most studies rely on imperfect proxy measures of unauthorized immigrant status (Richardson et al. 2020). Existing evidence suggests that, compared to documented Hispanic foreign-born and U.S.-born mothers, Hispanic unauthorized immigrant mothers have similar or lower levels of preterm birth and low birthweight but higher levels of delivery complications and postpartum depression (Richardson et al. 2020). Access to public benefits programs promotes health, but many immigrant families are ineligible. Providing access to Medicaid for pregnant undocumented immigrants improves prenatal care utilization and may improve birth outcomes for Hispanic infants (Perreira and Pedroza 2019).

Among Hispanic families, immigration enforcement and anti-immigrant bias are associated with adverse infant outcomes. Among both foreign-born and U.S.born Hispanic women, mothers who are exposed to greater levels of immigration 
enforcement during pregnancy are more likely to have low birthweight (Perreira and Pedroza 2019) and preterm babies (Ro, Bruckner, and Duquette-Rury 2020). Anti-immigrant rhetoric and interpersonal discrimination are also associated with worse outcomes. After the 2016 election, which was characterized by anti-immigrant rhetoric and increases in hate crimes, rates of preterm birth increased among Hispanic women, particularly foreign-born women (Krieger et al. 2018). These studies are methodologically rigorous, although effects on birth outcomes are relatively small.

\section{From Early to Middle Childhood}

During early and middle childhood, disparities in cardiovascular risk factors emerge. Hispanic children have high levels of overweight and obesity, inflammation, diabetes, and asthma (U.S. Census Bureau 2019). Compared to NH white children, Hispanic children are less likely to get adequate sleep, more likely to have more than two hours of screen time each day, and less likely to participate in sports (U.S. Census Bureau 2019). These health behaviors are associated with higher body mass index (BMI) and cardiovascular risk (Ochoa and Berge 2017).

\section{Social position}

While Hispanic girls and boys have similar rates of being overweight, boys have higher risk of obesity (Dixon, Peña, and Taveras 2012). Hispanic boys also have higher rates of prediabetes/diabetes and elevated blood pressure and, on average, have a higher overall cardiovascular risk profile, compared to Hispanic girls (Isasi et al. 2016). The sex disparity in obesity is larger in preschool and elementary school and narrows as Hispanic children age (Isasi et al. 2016).

Among Hispanic youth, lower SES is associated with higher BMI (Ochoa and Berge 2017); inflammation (Slopen et al. 2019); and allostatic load, a multisystem measure of physiological stress (Gallo et al. 2019). As of June 2020, more than one-third of Hispanic households with children report low or very low food security (Schanzenbach and Pitts 2020), which is associated with less access to healthy foods and higher rates of obesity (Ochoa and Berge 2017).

The immigrant paradox is evident in cardiovascular outcomes: foreign-born nativity and lower acculturation are protective against cardiovascular risk and asthma. First-generation Hispanic children have the lowest rates of obesity (Dixon, Peña, and Taveras 2012). First- and second-generation children have lower rates of asthma than third-generation children (U.S. Census Bureau 2019). Despite these advantages during childhood, first- and second-generation children's health advantages may erode as they age: Hispanic children with foreignborn parents are more likely than those with U.S.-born parents to have metabolic syndrome (Slopen et al. 2019), a risk factor for poor adult health.

Health differences by Hispanic background, which begin before birth, become entrenched during childhood. Among Hispanic children, Puerto Rican 
children have the highest average BMI and highest rates of asthma, while Mexican-origin and Central American-origin children have the lowest (Blewett et al. 2019).

No studies exist of the associations between cardiovascular risk and skin color or race in Hispanic children. However, darker-toned Hispanic young adults have higher cardiometabolic risk than their lighter-toned peers; this association is stronger for U.S.-born Hispanics than for foreign-born Hispanics (Wassink, Perreira, and Harris 2017).

\section{Social contexts}

As Hispanic children enter middle childhood, family structure and cohesion continue to have protective effects on health. Young Hispanic children who live in two-parent households have lower BMI than those in single-parent households (Blewett et al. 2019). Almost half of Hispanic families eat dinner together every day, and three-quarters eat dinner together at least four days per week (U.S. Census Bureau 2019). Family mealtime protects against overweight and obesity (Ochoa and Berge 2017). Additionally, low rates of smoking among Hispanic parents are protective against asthma and obesity (Ochoa and Berge 2017). Some aspects of home life increase cardiometabolic risk, however. For example, Hispanic parents are more likely than NH white parents to engage in feeding practices that are associated with overweight/obesity (Ochoa and Berge 2017).

Hispanic children who live in lower-income and less-safe neighborhoods are less likely to engage in regular physical activity, are more likely to be overweight/ obese (Ochoa and Berge 2017), and are more likely to have asthma (DePriest and Butz 2017) than those in more advantaged neighborhoods. Air pollution at home and at school (e.g., traffic-related pollutants, pesticides, mold, and animal allergens indoors) are associated with increased asthma prevalence and severity for Hispanic youth (DePriest and Butz 2017).

Hispanic children's psychosocial stress, emotional distress, and exposure to adverse childhood experiences (ACEs) are also associated with increased risk of asthma (DePriest and Butz 2017). Furthermore, parents'stressful experiences and mental health before, during, and after pregnancy are associated with children's asthma risk (DePriest and Butz 2017) and obesity-related behaviors in early to middle childhood (Isasi et al. 2016).

\section{Political and legal contexts}

Although no studies exist of associations between parents' unauthorized immigrant status and cardiometabolic outcomes, unauthorized immigrant families' low SES, high rates of food insecurity, and low preschool enrollment could place children at risk of poor cardiovascular health later in life (Ochoa and Berge 2017). Children with unauthorized immigrant parents have lower parent-rated health status and underutilize preventive medical and dental care, compared to children with U.S.-born parents (Gelatt 2016). 
An increasing number of studies examine the effects of immigration enforcement on children's physical and mental health outcomes. Hispanic parents who perceive their state immigrant policy climate as less welcoming report that their children have worse overall physical health (Perreira and Pedroza 2019). Children who experience deportation of a family member experience financial hardship and trauma and have high levels of both internalizing (e.g., depression or anxiety) and externalizing problems (e.g., conduct disorders and aggressive behavior) (Rojas-Flores et al. 2017). Immigration enforcement is also associated with worse mental health and cardiovascular health for Hispanic parents (Perreira and Pedroza 2019).

Evidence on the associations between discrimination and physical health in Hispanic children is mixed, likely because physical health problems may not emerge until adulthood. Youth who experience greater discrimination have higher allostatic load, cortisol levels, and asthma prevalence, as well as worse sleep and more unhealthy diets (Cave et al. 2020). Hispanic children whose mothers report experiencing more frequent ethnic discrimination are more likely to have low-grade inflammation (a marker of stress and allostatic load) but are not at increased risk of metabolic syndrome or overweight/obesity (Slopen et al. 2019).

\section{From Adolescence to Emerging Adulthood}

Much of the research on Hispanic health from adolescence to young adulthood focuses on mental health, substance use, and sexual health. Hispanic youth are less likely than NH white and NH Black youth to be diagnosed with mental, emotional, developmental, or behavioral problems (U.S. Census Bureau 2019) and have lower parent-reported distress (Blewett et al. 2019). However, Hispanic adolescents themselves report higher depression and PTSD symptoms than NH youth (Gallo et al. 2019). In high school, almost one-quarter of Hispanic females report suicidal ideation, and 10 percent report a suicide attempt (Centers for Disease Control and Prevention [CDC], n.d.). Hispanic youth have similar rates of substance use as $\mathrm{NH}$ white youth, and higher rates than NH Black youth (CDC, n.d.). Hispanic youth of all ages are less likely than NH white youth to receive needed mental health care (Lawton and Gerdes 2014). Levels of depression and anxiety symptoms are similar across Hispanic background groups (Perreira et al. 2019). Hispanic adolescents are as likely as other racial/ethnic groups to be sexually active but more likely than $\mathrm{NH}$ white youth to report risky sexual behavior (having first sexual intercourse before age 13, using no contraception at their most recent sexual intercourse) (CDC, n.d.).

\section{Social position}

Female Hispanic youth have higher risk of depression and suicidality (Scott, Wallander, and Cameron 2015) and eating disorders (Rodrigues 2017) than male 
Hispanic youth, while males have higher risk of risky sexual behavior compared to females (Killoren and Deutsch 2014). Minimal data exist on LGBTQ youth by race/ethnicity. In multiethnic U.S. samples, LGBTQ youth engage in more risky sexual behaviors and substance use (CDC, n.d.) and have worse mental health than heterosexual youth (Toomey et al. 2017). For Hispanic LGBTQ youth, homophobic and transphobic discrimination can compound the negative health effects of racial/ethnic discrimination (Toomey et al. 2017).

In adolescence, lower SES is associated with earlier sexual debut and more sexual partners (Carlson et al. 2014) and with worse mental health (Lawton and Gerdes 2014). Compared to Hispanic youth with U.S.-born parents, Hispanic youth with foreign-born parents have better mental health (U.S. Census Bureau 2019), less risky sexual behavior (Killoren and Deutsch 2014), and lower risk of intimate partner violence (Sabina, Cuevas, and Cotignola-Pickens 2016). In contrast, acculturation and acculturative stress are associated with worse mental health, higher risk of substance use, and higher rates of eating disorders (Rodrigues 2017; Kim et al. 2018). Biculturalism and ethnic identity are protective for mental health (Kim et al. 2018).

Hispanic youth with darker skin tones or who are Black have higher rates of internalizing and externalizing problems than those with lighter skin tones (Calzada, Kim, and O'Gara 2019). Darker-toned Hispanic youth are also more likely to be punished, suspended, and expelled from school, and are more likely to come into contact with the criminal justice system as adolescents (Calzada, Kim, and O’Gara 2019).

\section{Social contexts}

The Hispanic cultural emphasis on family (i.e., familism) may make family risk and protective factors more salient for Hispanic adolescents than for NH adolescents (Lawton and Gerdes 2014). Familism, family functioning, family cohesion, and Hispanic cultural affirmation and maintenance are associated with better mental health (Kim et al. 2018) and with lower rates of intimate partner violence (Sabina, Cuevas, and Cotignola-Pickens 2016), depression (Scott, Wallander, and Cameron 2015), and eating disorders (Rodrigues 2017).

Schools and neighborhoods with high proportions of Black and Hispanic residents are typically resource poor. Hispanic youth are exposed to higher levels of neighborhood disadvantage than their NH white and NH Asian peers, but lower levels than their NH Black peers (Carlson et al. 2014). Neighborhood disadvantage, poverty, and violence are associated with poor mental health outcomes (Lawton and Gerdes 2014) and risky sexual behavior (Carlson et al. 2014).

Trauma is a risk factor for adolescent mental health, eating disorders, substance use, risky sexual behavior, and intimate partner violence (Sabina, Cuevas, and Cotignola-Pickens 2016; Rodrigues 2017; Scott, Wallander, and Cameron 2015). Hispanic youth are more likely to have one or more ACEs, compared to $\mathrm{NH}$ white youth, and have higher rates of polyvictimization (experiencing multiple forms of trauma) (U.S. Census Bureau 2019). Among Hispanics, the risk of ACEs is lower for those in families with two parents (vs. one parent), 
foreign-born (vs. U.S.-born) parents, higher income, and lower parent education (Caballero et al. 2017).

\section{Political and legal contexts}

Children and adolescents with unauthorized immigrant mothers experience more trauma (Rojas-Flores et al. 2017) and have higher levels of internalizing and externalizing problems than children with lawfully present mothers (Kim et al. 2018). For children of unauthorized immigrant mothers, legal status may have a causal effect on mental health. After DACA provided temporary legal status for undocumented Hispanic young adults, their own and their children's mental health improved (Perreira and Pedroza 2019).

For Hispanic youth and their parents, immigration enforcement provokes stress and fear and negatively impacts mental health (Perreira and Pedroza 2019). Youth who report higher perceived vulnerability to immigration enforcement have more anxiety and problems with sleep (Eskenazi et al. 2019). After a parent, family member, or friend is deported, youth experience psychological distress and more internalizing and externalizing problems (Perreira and Pedroza 2019). After parental deportation, adolescents are forced to take on adult roles within their families, including caring for siblings and working to help the family meet their living expenses; they may be left as the sole guardian of younger siblings if all of the adults in their household are deported (Rojas-Flores et al. 2017). Youth whose family members are arrested for nonimmigration offenses also experience trauma and poor mental health. The parental incarceration rate for Hispanic youth is almost three times that of NH white youth (Davis and Shlafer 2017). Parental incarceration is associated with mental health diagnoses, suicidal ideation, and suicide attempts (Davis and Shlafer 2017). Hispanic adolescents who experience more racial/ethnic discrimination have lower self-esteem and higher levels of substance use, depression, and anxiety (Cave et al. 2020). Stronger Hispanic ethnic identity (Kim et al. 2018) and higher neighborhood/ school coethnic concentration (Kang 2019) can protect youth against the harmful mental health effects of discrimination.

\section{Protecting the Health of Hispanic Children in the Age of COVID-19}

Most Hispanic children are born healthy, demonstrate high levels of prosocial skills in early childhood, and have few externalizing behavior problems. At the same time, cardiovascular health risks (e.g., overweight, asthma, and diabetes) in Hispanic children emerge by preschool entry and continue through middle childhood into adolescence and early adulthood. At the onset of adolescence, symptoms of depression and anxiety become prevalent.

Consistent with the literature on the immigrant paradox, foreign-born nativity and the maintenance of ethnic identities and cultural values protect the health of 
Hispanic children of all ages. Two-parent family structures, family cohesiveness, and family support also protect the health and development of Hispanic children. However, low SES, residence in impoverished or disadvantaged neighborhoods, and sociopolitical contexts that increase exposure to discrimination and reduce access to resources undermine the positive health influences of Hispanic children's family environments. These risks may be particularly salient for Puerto Rican children who have some of the poorest health outcomes of all Hispanic children and for Black Hispanic children or Hispanic children with darker skin tones who are likely to be racialized and exposed to discrimination. Puerto Ricans are U.S.-born citizens and have access to a variety of public assistance benefits; their health disadvantages likely stem from poverty, residential segregation, racialization, and discrimination (Henry-Sanchez and Geronimus 2013).

Overall, the research on Hispanic children's health reveals the centrality of structural vulnerabilities to health. The socio-cultural assets and adaptations of Hispanic families are not sufficient on their own to overcome the deleterious consequences of social stratification and the institutions that reify that stratification.

The COVID-19 pandemic further underscores the structural vulnerabilities undermining Hispanic children's health. In comparison to NH white children, Hispanic children are at higher risk of exposure to SARS-CoV-2, the virus that causes COVID-19. In addition, their health and development may be compromised by the socioeconomic disruptions rooted in the COVID-19 pandemic.

Hispanic children's high risk of exposure to COVID-19 reflects their parents' socioeconomic position in the United States. As discussed in this volume (Guzman, Thomson, and Ryberg, this volume), Hispanic children are more likely to live in poverty and in overcrowded housing conditions where COVID-19 can more easily spread. Most importantly, their parents are overrepresented among essential workers who cannot work remotely from home and whose jobs require extensive social contact that carries significant contagion risk. Among Hispanics in the labor force, 24 percent are employed in service occupations, including health care, food preparation, and building or grounds maintenance (Bureau of Labor Statistics [BLS] 2020); 17 percent are in natural resources (e.g., farming and fishing), construction, and maintenance; and 16 percent are in production and transportation (BLS 2020). Foreign-born workers are also overrepresented among essential workers (Gelatt 2020). Thus, the children of Hispanic immigrant parents may be among the most at risk of exposure to COVID-19.

While severe COVID-19 seems, at this point, to be rare in children, preexisting conditions such as asthma, diabetes, and obesity have been associated with increased severity (CDC 2020). Consequently, the high prevalence of these conditions among Hispanic children, especially Puerto Rican children, may increase their risks of severe COVID-19. The risk of severe illness in children can also be exacerbated by delays in testing, diagnosis, and treatment associated with structural inequities in access to care for Hispanic children (Perreira, Allen, Oberlander, this volume).

However, the greatest risk to children's health from the COVID-19 pandemic may stem from increases in children's poverty and social isolation and concomitant 
increases in adverse childhood experiences. Child poverty has been associated with numerous deleterious consequences for children's health and development (National Academies of Sciences, Engineering, and Medicine 2019), and the COVID-19 pandemic has had severe economic consequences for Hispanic families, especially families that include noncitizens (Gonzalez et al. 2020). Approximately 60 percent of Hispanic adults live in families where someone has lost a job, work hours, or work-related income because of the pandemic; 50 percent have experienced material hardship in the past 30 days, including food insecurity and housing insecurity. Social isolation, which can result from stay-at-home orders and school closures, is known to increase the risk of depression and anxiety in children (Loades et al. 2020). Moreover, adverse childhood experiences (e.g., the death of a parent or domestic violence), which may stem from the pandemic, have also been associated with mental health problems in children and with adult morbidity and mortality (Middlebrooks and Audage 2008).

\section{Conclusion}

To improve the health and development of Hispanic children, policy-makers and the communities they serve must strive for health equity (Braveman 2014). To do so, policy-makers must address social and economic injustices that lead to declines in health across immigrant generations and persistent racial/ethnic health disparities between NH white and Hispanic Americans. Addressing these injustices will require substantial investments in efforts to eliminate exclusionary policies and practices; to build communities that support integration and multiculturalism; and to strengthen local, state, and federal government programs to reduce poverty (Perreira and Pedroza 2019; National Academies of Sciences, Engineering, and Medicine 2019).

\section{References}

Blewett, Lynn A., Julia A. Rivera Drew, Miriam L. King, and Kari C.W. Williams. 2019. IPUMS health surveys: National Health Interview Survey, version 6.4 [Dataset]. Minneapolis, MN: IPUMS.

Braveman, Paula. 2014. What is health equity: And how does a life-course approach take us further toward it? Maternal and Child Health Journal 18 (2): 366-72.

Bronfenbrenner, Urie, ed. 2005. Making human beings human: Bioecological perspectives on human development. Thousand Oaks, CA: Sage Publications.

Bureau of Labor Statistics (BLS). 2020. Foreign-born workers: labor force characteristics - 2019. USDL20-0922. Washington, DC: U.S. Department of Labor.

Caballero, Tania Maria, Sara B. Johnson, Cara R. Muñoz Buchanan, and Lisa Ross DeCamp. 2017. Adverse childhood experiences among Hispanic children in immigrant families versus US-native families. Pediatrics 140 (5): e20170297.

Calzada, Esther J., Yeonwoo Kim, and Jaimie L. O'Gara. 2019. Skin color as a predictor of mental health in young Latinx children. Social Science \& Medicine 238:112467.

Carlson, Daniel L, Thomas L. McNulty, Paul E Bellair, and Stephen Watts. 2014. Neighborhoods and racial/ethnic disparities in adolescent sexual risk behavior. Journal of Youth and Adolescence 43 (9): $1536-49$. 
Cave, Leah, Matthew N. Cooper, Stephen R. Zubrick, and Carrington C. J. Shepherd. 2020. Racial discrimination and child and adolescent health in longitudinal studies: A systematic review. Social Science \& Medicine 250:112864.

Centers for Disease Control and Prevention (CDC). 2020. People at increased risk of severe illness. Available from https://www.cdc.gov/coronavirus/2019-ncov/need-extra-precautions/ (accessed 20 June 2020).

Centers for Disease Control and Prevention (CDC). n.d. Youth online. Available from https://nccd.cdc .gov/youthonline/App/Default.aspx (accessed 20 June 2020).

Clarke, Wyatt, Kimberly Turner, and Lina Guzman. 2017. One quarter of Hispanic children in the United States have an unauthorized immigrant parent. Bethesda, MD: National Research Center on Hispanic Children and Families.

Coleman-Jensen, Alisha, Matthew P. Rabbitt, Christian A. Gregory, and Anita Singh. 2017. Statistical supplement to household food security in the United States in 2016. AP-077. Washington, DC: United States Department of Agriculture.

Davis, Laurel, and Rebecca J. Shlafer. 2017. Mental health of adolescents with currently and formerly incarcerated parents. Journal of Adolescence 54:120-34.

DePriest, Kelli, and Arlene Butz. 2017. Neighborhood-level factors related to asthma in children living in urban areas. Journal of School Nursing 33 (1): 8-17.

DeSisto, Carla L., and Jill A. McDonald. 2018. Variation in birth outcomes by mother's country of birth among Hispanic women in the United States, 2013. Public Health Reports 133 (3): 318-28.

Dixon, Brittany, Michelle-Marie Peña, and Elsie M. Taveras. 2012. Lifecourse approach to racial/ethnic disparities in childhood obesity. Advances in Nutrition 3 (1): 73-82.

Elder, Glen H., Monica Kirkpatrick Johnson, and Robert Crosnoe. 2003. The emergence and development of life course theory. In Handbook of the life course, eds. Jeylan T. Mortimer and Michael J. Shanahan, 3-19. Boston, MA: Springer U.S.

Eskenazi, Brenda, Carolyn A. Fahey, Katherine Kogut, Robert Gunier, Jacqueline Torres, Nancy A. Gonzales, Nina Holland, and Julianna Deardorff. 2019. Association of perceived immigration policy vulnerability with mental and physical health among US-born Latino adolescents in California. JAMA Pediatrics 173 (8): 744-53.

Fuller, Brian, Margaret Bridges, Edward Bein, Heeju Jang, Sunyoung Jung, Sophia Rabe-Hesketh, Neal Halfon, and Alice Kuo. 2009. The health and cognitive growth of Latino toddlers: At risk or immigrant paradox? Maternal and Child Health Journal 13:755-68.

Gallo, Linda C., Scott C. Roesch, Julia I. Bravin, Kimberly L. Savin, Krista M. Perreira, Mercedes R. Carnethon, Alan M. Delamater, Christian R. Salazar, Maria Lopez-Gurrola, and Carmen R. Isasi. 2019. Socioeconomic adversity, social resources, and allostatic load among Hispanic/Latino youth: The study of Latino youth. Psychosomatic Medicine 81 (3): 305-12.

García Coll, Cynthia, Keith Crnic, Gontron Lamberty, Barbara Hanna Waski, Renee Jenkins, Heidie Vásquez García, and Harriet Pipes McAdoo. 1996. An integrative model for the study of developmental competencies in minority children. Child Development 67 (5): 1891-1914.

Gelatt, Julia. 2016. Immigration status and the healthcare access and health of children of immigrants. Social Science Quarterly 97 (3): 540-54.

Gelatt, Julia. 2020. Immigrant workers: Vital to the U.S. COVID-19 response, disproportionately vulnerable. Washington, DC: Migration Policy Institute.

Gonzalez, Dulce, Michael Karpman, Genevieve M. Kenney, and Stephen Zuckerman. 2020. Hispanic adults in families with noncitizens disproportionately feel the economic fallout from COVID-19. Washington, DC: Urban Institute.

Guzman, Lina, Dana Thomson, and Renee Ryberg. 2021. Understanding the influence of Latino diversity over child poverty in the United States. The ANNALS of the American Academy of Political and Social Science (this volume).

Harris, Rebeca Alvarado, and Hudson P. Santos Jr. 2020. Maternal depression in Latinas and child socioemotional development: a systematic review. PLOS ONE 15 (3): e0230256.

Henry-Sanchez, Brenda L., and Arline T. Geronimus. 2013. Racial/ethnic disparities in infant mortality among U.S. Latinos: A test of the segmented racialization hypothesis. Du Bois Review 10 (1): 205-31.

Isasi, Carmen R., Christina M. Parrinello, Guadalupe X. Ayala, Alan M. Delamater, Krista M. Perreira, Martha L. Daviglus, John P. Elder, Ashley N. Marchante, Shrikant I. Bangdiwala, Linda Van Horn, and 
Mercedes R. Carnethon. 2016. Sex differences in cardiometabolic risk factors among Hispanic/Latino youth. Journal of Pediatrics 176:121-27.e1.

Kane, Jennifer B., Gandarvaka Miles, Jennifer Yourkavitch, and Katherine King. 2017. Neighborhood context and birth outcomes: Going beyond neighborhood disadvantage, incorporating affluence. SSM Population Health 3:699-712.

Kang, Jeehye. 2019. Do co-ethnic concentrated neighborhoods protect children with undocumented parents? Focusing on child behavioral functioning. Social Science Research 81:132-43.

Killoren, Sarah E., and Arielle R. Deutsch. 2014. A longitudinal examination of parenting processes and Latino youth's risky sexual behaviors. Journal of Youth and Adolescence 43 (12): 1982-93.

Kim, Su Yeong, Seth J. Schwartz, Krista M. Perreira, and Linda P. Juang. 2018. Culture's influence on stressors, parental socialization, and developmental processes in the mental health of children of immigrants. Annual Review of Clinical Psychology 14:343-70.

Krieger, Nancy, Mary Huynh, Wenhui Li, Pamela D. Waterman, and Gretchen Van Wye. 2018. Severe sociopolitical stressors and preterm births in New York City: 1 September 2015 to 31 August 2017. Journal of Epidemiology and Community Health 72 (12): 1147-52.

Lawton, Kathryn, and Alyson Gerdes. 2014. Acculturation and Latino adolescent mental health: Integration of individual, environmental, and family influences. Clinical Child \& Family Psychology Review 17 (4): 385-98.

Loades, Maria Elizabeth, Eleanor Chatburn, Nina Higson-Sweeney, Shirley Reynolds, Roz Shafran, Amberly Brigden, Catherine Linney, Megan Niamh McManus, Catherine Borwick, and Esther Crawley. 2020. Rapid systematic review: the impact of social isolation and loneliness on the mental health of children and adolescents in the context of COVID-19. Journal of the American Academy of Child \& Adolescent Psychiatry 59 (11): 1218-39.

Mendez-Smith, Julia, Danielle Crosby, and Christina Stephens. 2021. Equitable access to high-quality early care and education: Opportunities to better serve young Hispanic children and their families. The ANNALSs of the American Academy of Political and Social Science (this volume).

Middlebrooks, Jennifer S., and Natalie C. Audage. 2008. The effects of childhood stress on health across the lifespan. Atlanta, GA: Centers for Disease Control and Prevention.

Migration Policy Institute. 2020. Deferred Action for Childhood Arrivals (DACA) data tools. Available from https://www.migrationpolicy.org/programs/data-hub/deferred-action-childhood-arrivals-dacaprofiles (accessed 20 June 2020).

Mukherjee, Soumyadeep, Mary Jo Trepka, Dudith Pierre-Victor, Raed Bahelah, and Tenesha Avent. 2016. Racial/ethnic disparities in antenatal depression in the United States: A systematic review. Maternal and Child Health Journal 20 (9): 1780-97.

Mydam, Janardhan, Richard J. David, Kristin M. Rankin, and James W. Collins. 2019. Low birth weight among infants born to Black Latina women in the United States. Maternal and Child Health Journal 23:538-46.

National Academies of Sciences, Engineering, and Medicine 2019. A roadmap to reducing child poverty. Washington, DC: The National Academies Press.

Ochoa, Alejandra, and Jerica M. Berge. 2017. Home environmental influences on childhood obesity in the Latino population: A decade review of literature. Journal of Immigrant and Minority Health 19 (2): $430-47$.

Office of Planning, Research \& Evaluation (OPRE). 2014. Survey data elements to unpack diversity of Hispanic populations. OPRE report \#2014-30. Washington, DC: U.S. Department of Health and Human Services, Administration for Children and Families.

Oropesa, R. S., Nancy S. Landale, and Marianne M. Hillemeier. 2015. Family legal status and health: Measurement dilemmas in studies of Mexican-origin children. Social Science b Medicine 138:57-67.

Padilla, Christina M., Natasha Cabrera, and Jerry West. 2017. The development and home environments of low-income Hispanic children: kindergarten to third grade. 2017-37. Bethesda, MD: National Research Center on Hispanic Children \& Families.

Padilla, Christina M., and Rebecca M. Ryan. 2020. School readiness among children of Hispanic immigrants and their peers: The role of parental cognitive stimulation and early care and education. Early Care and Education among Latino Families; Access, Utilization, and Impacts 52:154-68.

Perreira, Krista M., Chenoa D. Allen, and Jonathan Oberlander. 2021. Access to health insurance and health care for Hispanic children in the United States. The ANNALS of the American Academy of Political and Social Science (this volume). 
Perreira, Krista M., Ashley N. Marchante, Seth J. Schwartz, Carmen R. Isasi, Mercedes R. Carnethon, Heather L. Corliss, Robert C. Kaplan, Daniel A. Santisteban, Denise C. Vidot, Linda Van Horn, and Alan M. Delamater. 2019. Stress and resilience: Key correlates of mental health and substance use in the Hispanic Community Health Study of Latino Youth. Journal of Immigrant and Minority Health 21 (1): 4-13.

Perreira, Krista M., and India J. Ornelas. 2011. The physical and psychological well-being of immigrant children. The Future of Children 21 (1): 195-218.

Perreira, Krista M., and Juan M. Pedroza. 2019. Policies of exclusion: Implications for the health of immigrants and their children. Annual Review of Public Health 40:147-66.

Richardson, Dawn M., Sarah B. Andrea, Amber Ziring, Cassandra Robinson, and Lynne C. Messer. 2020. Pregnancy outcomes and documentation status among Latina women: A systematic review. Health Equity 4 (1): 158-82.

Ro, Annie, Tim A. Bruckner, and Lauren Duquette-Rury. 2020. Immigrant apprehensions and birth outcomes: Evidence from California birth records 2008-2015. Social Science d Medicine 249:112849.

Rodrigues, Myanca. 2017. Do Hispanic girls develop eating disorders? A critical review of the literature. Hispanic Health Care International 15 (4): 189-96.

Rojas-Flores, Lisseth, Mari L. Clements, J. Hwang Koo, and Judy London. 2017. Trauma and psychological distress in Latino citizen children following parental detention and deportation. Psychological Trauma: Theory, Research, Practice, and Policy 9 (3): 352-61.

Sabina, Chiara, Carlos A. Cuevas, and Heather M. Cotignola-Pickens. 2016. Longitudinal dating violence victimization among Latino teens: Rates, risk factors, and cultural influences. Journal of Adolescence 47:5-15.

Schanzenbach, Diane, and Abigail Pitts. 2020. Food insecurity during COVID-19 in households with children: Results by racial and ethnic groups. Evanston, IL: Institute for Policy Research, Northwestern University.

Scott, Sarah M., Jan L. Wallander, and Linda Cameron. 2015. Protective mechanisms for depression among racial/ethnic minority youth: Empirical findings, issues, and recommendations. Clinical Child and Family Psychology Review 18 (4): 346-69.

Slopen, Natalie, Garrett Strizich, Simin Hua, Linda C. Gallo, David H. Chae, Naomi Priest, Matthew J. Gurka, Shrikant I. Bangdiwala, Julia I. Bravin, Earle C. Chambers, Martha L. Daviglus, Maria M. Llabre, Mercedes R. Carnethon, and Carmen R. Isasi. 2019. Maternal experiences of ethnic discrimination and child cardiometabolic outcomes in the Study of Latino Youth. Annals of Epidemiology 34:52-57.

Suárez-Orozco, Carola, Frosso Motti-Stefanidi, Amy Marks, and Dalal Katsiaficas. 2018. An integrative risk and resilience model for understanding the adaptation of immigrant-origin children and youth. American Psychologist 73 (6): 781-96.

Taylor, Lauren A., Annabel Xulin Tan, Caitlin E. Coyle, Chima Ndumele, Erika Rogan, Maureen Canavan, Leslie A. Curry, and Elizabeth H. Bradley. 2016. Leveraging the social determinants of health: What works? PLoS One 11 (8): e0160217.

Toomey, Russell B., Virginia W. Huynh, Samantha K. Jones, Sophia Lee, and Michelle Revels-Macalinao. 2017. Sexual minority youth of color: A content analysis and critical review of the literature. Journal of Gay \& Lesbian Mental Health 21 (1): 3-31.

Torres, Jacqueline M., Maria Elena and D. Young. 2016. A life-course perspective on legal status stratification and health. SSM - Population Health 2:141-48.

U.S. Census Bureau. 2019. 2018 NSCH topical data [dataset]. Washington, DC: U.S. Census Bureau.

U.S. Census Bureau. 2020. Quick facts: Puerto Rico. Available from https:/www.census.gov/quickfacts/PR (accessed 20 June 2020).

Vrijheid, Martine, Maribel Casas, Mireia Gascon, Damaskini Valvi, and Mark Nieuwenhuijsen. 2016. Environmental pollutants and child health-A review of recent concerns. International Journal of Hygiene and Environmental Health 219 (4): 331-42.

Wassink, Joshua, Krista M. Perreira, and Kathleen M. Harris. 2017. Beyond race/ethnicity: Skin color and cardiometabolic health among Blacks and Hispanics in the United States. Journal of Immigrant and Minority Health 19 (5): 1018-26. 